\title{
Catastrophic Shocks and Capital Markets: A Comparative Analysis by Disaster and Sector
}

\author{
ANDREW WORTHINGTON \\ School of Economics and Finance, Queensland University of Technology, \\ QLD 4001, Australia \\ and \\ ABBAS VALADKHANI \\ School of Economics and Information Systems University of Wollongong, \\ NSW 2522 Australia
}

Corresponding Author's Address:

Dr Abbas Valadkhani

School of Economics and Information Systems

University of Wollongong,

Wollongong, NSW 2522,

Australia

Email: abbas@uow.edu.au

Tel: +612-4221 4022

Fax: +612-4221 3725

Keywords: Intervention Analysis; Capital Markets; Natural Disasters. 


\title{
Catastrophic Shocks and Capital Markets: A Comparative Analysis by Disaster and Sector
}

\begin{abstract}
This paper provides an analysis of the impact of natural, industrial and terrorist disasters on the Australian capital market using the Box and Tiao intervention analysis and the data on daily returns in the following ten market sectors: consumer discretionary, consumer staples, energy, financial, health care, industrial, information technology, materials, telecommunication services and utilities. Inter alia, we have found that the shocks provided by natural disasters have an influence on market sector returns, depending upon the sector in question. The sectors most sensitive to disasters of any type are the consumer discretionary, financial services and materials sectors while the most significant single event during the past eight years would appear to be the September 11 terrorist attack, at least in terms of its impact upon the capital market.
\end{abstract}

\section{Introduction}

Recent events have renewed interest in the financial impact of disasters and catastrophes. Most notably, the September 11 terrorist attacks on the New York World Trade Centre showed how catastrophic events such as this adversely affect both domestic and international capital markets through the creation of uncertainty and panic, the promotion of extreme price volatility and the partial destruction of global financial centres (Chen and Siems 2002). But while disasters and catastrophes of a human origin such as terrorist acts have dominated public awareness of late, natural disasters and catastrophes (including floods, storms, bushfires, hurricanes, cyclones, tsunamis and earthquakes) continue to cause severe and increasing damage to global economies and disruption to international financial activity (FEMA 2003, EMA 2003). Similarly, industrial disasters and catastrophes of unintended human origin have shown themselves just as capable of seriously disrupting financial systems. Through the disruption of production and consumption, the interruption of domestic 
and international trade, the destruction of infrastructure, buildings and vehicles, and the creation of uncertainty in the minds of investors, producers and consumers alike, disasters and catastrophes, whether of human or natural origin, have the clear and demonstrated potential to adversely affect financial activity and wellbeing. For example Fairbairn (1998) examines the devastating effects of natural disasters on social and economic infrastructure and the productive base in a number of Pacific island countries. He proposes a number of measures which can be implemented to mitigate economic losses. More recently the effects of natural disasters are of growing interest to East Asian Economies particularly after the December 2004 tsunami which was among the deadliest disasters in modern history, killing well over 240,000 people. Although this paper does not make an attempt to model the effects of natural disasters on financial markets in East Asian countries, the adopted Box and Tiao intervention technique in this paper can provide a useful analytical framework for this purpose.

In response to these concerns, an emergent literature has arisen to examine the financial impact of natural events, disasters and catastrophes on capital markets. But to date, most of this research has focused more narrowly on the property-liability insurance industry [see, for example, Shelor et al. (1992), Aiuppa et al. (1993), Lamb (1995), Angbazo and Narayanan (1996) and Cagle (1996)] . Within this industry, two opposing, but not mutually exclusive, hypotheses exist. The first and most obvious is that insurers, because of the payments made to policyholders for their damages, incur large losses. While at least some of this is offset by reinsurance, for the most part the expectation is that these losses should cause insurance stocks to decline at the time of the disaster. The less obvious effect is that insurers benefit from an isolated catastrophic event because of increased demand for their products, through an increase in both required coverage and additional premium earnings.

The net effect on property-liability insurer stock values thus varies according to the relative strength of these two opposing forces. Shelor et al. (1992) and Aiuppa et al. (1993), 
for example, both concluded that insurer stock values increased after California's Loma Prieta earthquake [insured loss USD2.5 billion] in part because high earthquake insurance rates and low perceived risk meant many property owners were uncovered at the time. Conversely, Angbazo and Narayanan (1996) and Lamb (1995) found that the large negative effect of Florida and Louisiana’s Hurricane Andrew [insured loss USD16.5 billion] was only slightly offset by the subsequent premium increases, and furthermore that the event even showed evidence of a contagion effect to insurers with no claims exposure in the hurricane affected states. Cagle (1996) concluded that South Carolina’s Hurricane Hugo [insured loss USD4.2 billion] caused a significant negative price reaction for insurers with high exposure and unaffected those with low exposure. Lastly at an aggregate level Worthington and Valadkhani (2004) have recently examined the impact and duration of natural disaster effects on the Australian equity market. The present study is in fact an extension of the work by Worthington and Valadkhani (2004) in that it quantifies such effects on the daily returns within various sectors in Australia’s capital markets.

It is clear that existing research into the financial impact of disasters and catastrophes suffers a number of limitations. First and foremost, there is the concentration on the property liability insurance industry, even though it is well known that disasters and catastrophes have a substantial impact on non-insurance industries and sectors (BTE 2001, FMA 2003, EMA 2003). For example, industries and sectors heavily dependent on consumer confidence or those reliant on international trade may be dealt a heavy blow through acts of terrorism, while those in natural disaster-affected areas may experience disruption to production and distribution through the destruction of essential infrastructure, buildings and vehicles. Second, nearly all past studies of the financial impact of disasters and catastrophes have tended to concentrate on natural events [see, for instance, Miller (1991), Shelor et al. (1992), Lamb (1995) and West (2003)]. While this is a logical outcome of the aforementioned focus 
on property-liability insurers and insurable losses, it ignores the increasingly alarming frequency of intended human acts such as terrorism and unintended human events such as industrial accidents and corporate collapses that likewise have the potential to bring about catastrophic financial shocks. Third, there has been the tendency to concentrate on single events [see, for example, Shelor et al. (1992), Aiuppa et al. (1993) and Cagle (1996)]. While this simplifies the analysis, single events may be susceptible to contamination to macroeconomic events independent of the disaster or catastrophe itself (West 2003). Moreover, valuable lessons are likely to be learned regarding the different impacts of disasters and catastrophes when several events are compared within a single study.

Accordingly, the purpose of this paper is to model the market sector impacts of catastrophes in Australia. Apart from the work by Worthington and Valadkhani (2004), the current study is believed to be the first financial study of disasters and catastrophes to use intervention analysis in an autoregressive moving average (ARMA) framework, and one of few studies of the financial impacts of disasters and catastrophes outside the United States. The paper itself is divided into four main areas. The second section explains the data employed in the analysis and presents some summary statistics. The third section discusses the methodology employed. The results are dealt with in the fourth section. The paper ends with some brief concluding remarks.

\section{Data and Summary Statistics}

Two sets of data are employed in the analysis. The first set is the daily closing prices for the ten Australian equity sector indices calculated by Morgan Stanley Capital International (MSCI): namely, consumer discretionary $(C N D)$, consumer staples $(C N S)$, energy ( $E N G)$, financial $(F I N)$, health care $(H L T)$, industrial $(I N D)$, information technology $(I N F)$, materials $(M T L)$, telecommunication services $(T E L)$ and utilities (UTL). The sample period for all 
indices ends on 2 July 2003 with $C N D, C N S, E N G$, FIN, HLT, IND and MTL commencing on 2 January 1995 (2,216 observations), UTL on 3 June 1996 (1,846 observations), TEL on 28 November 1996 (1,457 observations) and INF on 31 May 2000 (804 observations). All data is obtained electronically from Bloomberg. The natural log of the relative price is computed for the closing prices to produce a time series of continuously compounded daily returns, such that $r_{t}=\log \left(p_{t} / p_{t-1}\right) \times 100$, where $p_{t}$ and $p_{t-1}$ represent the market price at time $t$ and $t-1$, respectively.

\section{$<$ TABLE 1 HERE $>$}

The second set of data comprises the most significant disasters affecting the Australian market during the period 2 January 1995 to 2 July 2003. While some of Australia's most devastating disasters are not included in this period, including Cyclone Tracey in 1974, the 1983 Ash Wednesday bushfires, and the 1989 Newcastle earthquake, it comprises the longest period where consistent daily price indices were available for most Australian equity sectors. Three categories of events are included: namely, natural disasters, industrial disasters and terrorist disasters, with events included on the basis that they provide potentially significant business impacts, primarily on the basis of sizeable insured and uninsured losses.

Two events are included in the category of 'natural disasters'. The first natural disaster is a severe hailstorm that struck southern Sydney on 14 April 1999. This hailstorm is now recognised by the Insurance Council of Australia as representing the largest insured loss for a single natural event in Australian history causing substantial damage (number of claims/estimated cost in brackets) to homes $(43,000 / \$ 300$ million $)$, motor vehicles (32,000/\$309 million), commercial buildings (3,000/\$220 million) and aircraft (numbers not recorded/\$109 million) in the Sydney region. It is accepted that total damages now surpass that caused by the Newcastle earthquake in December 1989 (\$1.124 billion in 1998 dollars) 
after the remaining anticipated costs such as business interruption are included. The second natural disaster recorded is bushfires that burned in NSW, the ACT, Victoria, Tasmania and Western Australia almost continuously from early October 2002 through to February 2003, culminating in a devastating blaze in Canberra on 18 January 2003. The Canberra fires, which are the country's second largest bushfire since Victoria's 1983 Ash Wednesday and $8^{\text {th }}$ worst natural disaster since 1967, left four people dead, scores injured, nearly 500 homes destroyed and hundreds more severely damaged, and total costs currently estimated at \$312 million.

Two events are also included in the category of 'industrial disasters'. The first of these is the Victorian gas supply crisis that started on 25 September 1998 following an explosion and fire at Esso’s Longford natural gas processing plant which killed two workers and cut the state's gas supply for about two weeks. The Royal Commission into the explosion found that Esso's failings on workplace safety and employee training contributed solely to the explosion which ripped through the natural gas processing plant in Victoria's south-east, while for two weeks after the blast Victorian businesses and households struggled to operate without gas in a crisis which was estimated to cost gas users nearly $\$ 1.3$ billion. The second industrial disaster occurred on 15 March 2001 when the major companies in the HIH Insurance group, Australia's second-largest general (non-life) insurer, were placed in provisional liquidation with unfunded liabilities of \$5 billion. Along with far-reaching implications for corporate governance and financial supervision of Australia’s largest financial and non-financial firms flowing from a Royal Commission, the collapse of HIH is recognised as the largest corporate failure to date and played an important role in worsening Australia's public liability and professional indemnity insurance crisis.

The final category comprises two 'terrorist disasters'. The first is the attack on New York’s World Trade Centre on 11 September 2001, which apart from killing 2,801 people caused significant and ongoing disruption to global business with profound implications for 
international economic, political and social stability into the foreseeable future. The second event occurred on 12 October 2002 when more than 200 people died, 88 of them Australians, when two bombs ripped through the Sari Club and Paddy's Bar in the tourist strip along Kuta Beach in Bali, Indonesia. While the direct economic and financial impacts of these two particular events are difficult to ascertain, it is recognised that they are both watersheds in Australian political, social and economic life.

Table 1 presents the descriptive statistics of the daily returns in each of the ten equity sectors. Sample means, medians, maximum and minimums, standard deviations, skewness, kurtosis and the Jacque-Bera statistic and $p$-value are reported. The lowest mean returns are in the information technology (0.0001) and materials (0.0001) sectors and the highest mean returns are for financial services (0.0004) and utilities (0.0004). The lowest minimum returns are in the information technology (-0.3339) and consumer discretionary (-0.1306) sectors, as are the highest maximum returns (2.5246 and 0.2002, respectively). The standard deviations of returns range from 0.0095 (financial services) to 0.0986 (information technology). On this basis, of the ten sectors the returns in the information technology, consumer durables and telecommunications sectors are the most volatile, with financial services, consumer staples and industrials being the least volatile.

By and large, the distributional properties of the daily returns appear non-normal. Returns in consumer durables $(C N D)$, heath care $(H L T)$ and information technology (INF) are significantly positively skewed (0.3981, 0.7183 and 20.8943 , respectively), indicating the greater probability of large increases in returns than decreases (that is, volatility clustering in daily returns). Conversely, returns in the financial services (FIN) and industrials (IND) sectors are significantly negatively skewed (-0.3369 and -0.3409). The kurtosis, or degree of excess, in all return series is also significantly large and greater than three, ranging from 4.5074 in 
materials $(M T L)$ to 537.3205 in information technology (INF), thereby indicating leptokurtic distributions.

The Jarque-Bera statistics and corresponding $p$-values in Table 1 are used to test the null hypotheses that the daily distribution of sector returns is normally distributed. All ten $p$ values are smaller than the .01 level of significance suggesting the null hypothesis can be rejected. These stock market returns are then not well approximated by the normal distribution. Unit root tests are conducted in Table 1 as a means of elaborating upon the time series properties of the return series and ensuring stationarity for the ARMA specification to follow. The ADF $t$-statistics reject the null hypotheses of a unit root at the .01 level assuming both constant only and constant and trend in all return series. For the KPSS tests of the null hypothesis of no unit root with constant only, For the KPSS tests of the null hypothesis of no unit root with constant only, the LM-statistic fails to exceed the asymptotic critical value at the .10 level for all series. We may conclude that the return series examined are stationary.

\section{Model Specification}

Since the time series data on sectoral returns are available in regularly spaced intervals and given the timing of the natural, industrial and terrorist disasters is known with certainty, intervention analysis can be used to examine the impact of disasters on the Australian capital market. Intervention analysis is based on the Box-Jenkins methodology in which an autoregressive moving average (ARMA) model is augmented by dummy variables to evaluate the effect(s) of extraordinary or abnormal events. Since first proposed by Box and Tiao (1975) this technique has been employed in a variety of financial contexts. For example, Ho and Wan (2002) used intervention analysis to test for structural breaks following the 1997 Asian financial crisis, Liu and Yu (2002) investigated the role of Taiwan's stock stabilization fund in countering market declines associated with foreign policy changes and Bhar (2001) and St. 
Pierre (1998) used it to examine the return and volatility dynamics of the Australian spot and futures markets and the volatility impacts of introducing option contracts, respectively. Likewise, intervention analysis has already found application in studies of natural disasters, including Fox's (1995, 1996) analysis of the impact of Hurricane Hugo on business environments.

The following ARMA process of order $(k, q)$ is specified (assuming stationary daily returns):

$$
\Phi_{k}(L)\left(1-\phi L^{r}\right) y_{t}=\mu+\Theta_{q}(L) \varepsilon_{t}+\beta D_{t}
$$

where $\Phi_{k}(L)$ represents a $k$-order polynomial lag operator, $\phi$ is a seasonal parameter, $r$ is the seasonal lag term, $y$ represents the market return in price defined as $\log \left(p_{t} / p_{t-1}\right), \mu$ is a constant, $\Theta_{q}(L)$ denotes a $q$-order polynomial lag operator, $\varepsilon$ is a white noise process, $k$ is the number of autoregressive (AR) terms, $q$ is the number of moving-average (MA) terms and $D_{t}$ are intervention dummy variables.

Three important specification issues arise in this model. First, as part of the modeling process one needs first to choose accurate values for $k, r$ and $q$ in the ARMA specification. While the identification of an appropriate ARMA model is not exact, as a rule of thumb the Akaike information (AIC) and Schwartz specification (SC) and the autocorrelation (AC) and partial autocorrelation (PAC) functions can be used to determine $q$ and $k$, respectively. The estimated model is then subjected to a range of diagnostic checks on the residuals to ensure that the model has properly accounted for all systematic variation in the time series. Second, the ARMA model specified should also capture any systematic underlying time series patterns, if any, in the data (of which seasonality is potentially the most obvious). This is important since systematic time series patterns in the fluctuations in the data need to be accounted for so as to accurately gauge the impact of the disasters. In order to address this 
possibility, equation (1) is augmented by a seasonal autoregressive term (Box et al. 1994). Lastly, it is also important under ARMA theory that the series being modeled is stationary. As shown in Table 1 unit root tests for the return series indicate stationarity. The general form of the equation used to model sector returns is then as follows:

$$
\left(1-\rho_{1} L-\rho_{2} L^{2}-\ldots \rho_{k} L^{k}\right)\left(1-\phi L^{r}\right) y_{t}=\mu_{0}+\Theta_{q}(L) \varepsilon_{t}+\sum_{j=1}^{n=6} \beta_{i j} D_{i t-j}+w_{t}
$$

where $\rho_{\mathrm{s}}$ are autoregressive parameters, $i$ denotes the $i$-th catastrophic event $(1=$ Sydney hail storm, 2 = Canberra bush fire, 3 = Victorian gas supply crisis, $4=\mathrm{HIH}$ collapse, $5=$ September 11, 6 = Bali bombing) and all other variables are as previously defined. In order to measure the impact of the $i$-th event on the dependent variable, we have considered the following scenarios: (i) each dummy variable takes on the value of one on the first day of the event declining linearly at the rate of 0.10 per day until it reaches zero after ten days and zero otherwise, (ii) each dummy variable is equal to 0.10 on the first day of the event increasing linearly at the rate of 0.10 per day until it reaches unity after ten days, and zero otherwise, (iii) each dummy variable takes on the value of unity on the day and the day after the first day of the event and otherwise zero, (iv) each dummy variable takes on the value of unity on the day of the event and otherwise zero. Among these, scenario (i) produced the most statistically appropriate results for all events and sectors on the basis of various model specification criteria, supporting the view that the impact of each event declines through time.

The magnitude and sign of the estimated coefficients on these six dummy variables indicates the mean effect of each disaster category on market sector return beyond what could have been expected from the discernible systematic pattern of data fluctuations in the ARMA model. The sign on the estimated coefficients will, of course, depend on the net impact of each type of natural disaster upon each sector. No particular sign on the estimated coefficients is then hypothesized. 
However, there is the real possibility that the effects of these catastrophic events may persist beyond the day of the event itself. Persistence in this model may be related to difficulty in ascertaining the likely losses associated with the natural disaster, lags in information dissemination from the disaster area or delays in forecasting the possible financial effects for firm, industries, sectors and the market as a whole. Currently, these effects are assumed to persist up to ten working days with the maximum and minimum effect occurring on the first and tenth days, respectively. Given the assumed mean reverting process in the Australian market returns, it is plausible to hypothesize that the effects will be all or nearly all exhausted during this period.

\section{Empirical Results}

The estimated coefficients, standard errors and $p$-values of the parameters for the ARMA regression models are provided in Table 2 . The dependent variables are the respective daily returns in the Australian consumer discretionary $(C N D)$, consumer staples $(C N S)$, energy (ENG), financial $(F I N)$, health care (HLT), industrial (IND), information technology (INF), materials $(M T L)$, telecommunication services $(T E L)$ and utilities $(U T L)$ sectors. Also included in Table 2 are statistics for the Akaike information (AIC) and Schwartz specification (SC) criterion as guides for model specification, the likelihood ratio (LR) test statistic as a test of model significance and the Durbin-Watson (DW) Ljung-Box (Q) and Breusch-Godfrey Lagrange multiplier (LM) test statistics for first and higher-order serial correlation in the residuals. White's heteroskedasticity test is used to test the null hypothesis of no heteroskedasticity against heteroskedasticity of some unknown form. Where the null hypothesis fails to be rejected ( $E N G, H L T, I N D, I N F$ and $U T L)$ conventional standard errors are presented in Table 2, whereas if the test is rejected (CND, CNS, FIN, MTL and TEL) White’s heteroskedastic consistent standard errors are used. 


\section{<TABLE 2 HERE $>$}

The results in these models appear sensible in terms of both the precision of the estimates and the signs on the coefficients. Different optimal $\operatorname{ARMA}(p, q)$ error processes are found to generate statistically acceptable models in each of the ten sectors. For example, in the model where $C N D$ is specified as the dependent variable a $\operatorname{ARMA}(4,4)$ error process is selected: that is, an autoregressive and moving average error process based on 1-4 day lagged residuals sufficiently accounts for the systematic variation in returns. Alternatively, a ARMA(1,1) model well fits the models where $I N F$ and $U T L$ are specified as the dependent variables. Seasonal autoregressive terms are also tested for inclusion in the final specification for each sector, with seasonal parameters (number of lags in brackets) included where CNS (9), ENG (5), FIN (4), HLT (4) and MTL (10) are specified as dependent variables. Likelihood ratio (LR) tests of the null hypothesis that all parameters are jointly zero are rejected at the .10 level or higher for all final specifications with the exception of $I N F$.

The ARMA intervention models also pass the conventional diagnostic tests. The Durbin-Watson (DW) statistic, especially considering the absence of lagged dependent variables in the regression model, is strongly suggestive of no first-order serial correlation. Moreover, the Ljung-Box $Q$-statistics (up to 36 lags) and the Breusch-Godfrey $L M$-statistics (5 lags) fail to reject the null hypotheses of no higher-order serial correlation and the autocorrelations and partial autocorrelations of the innovations in the ARMA models (not shown) are all nearly zero with insignificant $Q$-statistics and large $p$-values. All estimated coefficients for the seasonal $\phi$, autoregressive $\rho$ and moving average $\theta$ terms are also statistically significant and the inverted AR and MA roots (not shown) have modulus less than one, indicating that the estimated ARMA models are stationary. Combined together, these tests indicate that no important forecasting power has been overlooked. Nonetheless, the scale-invariant forecasting accuracy varies markedly across the different sectors, with the 
ARMA models used being most accurate (Thiel inequality coefficient in brackets) in forecasting returns in the consumer staples (0.0649) and materials (0.0830) sectors and least accurate in the information technology $(0.4387)$ and health care $(0.2366)$ sectors.

Consider the results for the financial services $(F I N)$ sector. In this model, the estimated coefficients for the Victorian gas supply crisis, the HIH collapse and the September 11 terrorist attack are negative and significant at the 5 percent level of significance or lower. The market effect with the largest economic impact is for September $11(-0.0237)$, followed by the gas supply crisis (-0.0162) and then the collapse of HIH (-0.0105). The estimated coefficients for the Sydney hail storm, the Canberra bushfires and the Bali bombing are not significant at any conventional level. Alternatively, in the materials (MTL) sector the estimated coefficients for the Sydney hail storm and the Canberra bushfires are significant (along with September 11) at the 10 percent level of significance or higher, with negative market effects from the latter two (-0.0070 and -0.0184 , respectively) and a positive effect from the former $(0.0232)$. Put differently, September 11 and the Canberra bushfires were associated with a 1.84 and 0.70 percent decline in the materials sector in the ten days following the event, while the Sydney hailstorm produced a positive market effect in the materials sector with an increase of 2.32 percent over the ensuing period. None of the estimated disasters coefficients are individually significant in the models where the returns for consumer staples, energy, healthy care, information technology, telecommunications and utilities are specified as the dependent variable.

Wald tests of the joint insignificance of the coefficients for each disaster category are also conducted and the results presented in Table 3. As shown, the null hypotheses of the joint insignificance of the invention variables for natural, industrial, terrorist and all disasters fail to be rejected for the consumer staples (CNS), energy (ENG), health care $(H L T)$, industrial (IND), telecommunications (TEL) and utilities (UTL) sectors. The null hypothesis of joint 
insignificance is rejected for terrorist and all disasters in the consumer discretionary (CND) sector, for industrial, terrorist and all disasters in the financial $(F I N)$ sector, for natural and industrial disasters in the information technology (INF) sector, and for natural, terrorist and all disasters in the materials (MTL) sector. We may conclude that the impact of natural disasters on market returns is largely restricted to the materials and information technology sectors, industrial disasters to the financial services and information technology sectors, terrorist disasters to the consumer discretionary, financial services and materials sectors, and disasters generally to the consumer discretionary, financial services and materials sectors. Of course, such findings only strictly apply to the six disasters specified in this particular analysis, and may well vary if other natural, industrial and terrorist events during the sample period were included.

The results indicate that different market sectors respond differently to exogenous market shocks in the form of disasters, whether of a natural or human origin. All other things being equal, sectors closely associated with claims on insurance policies from the destruction of buildings and infrastructure and the disruption to business activity $(F I N)$, those involved in the provision of materials for reconstruction (MTL), and those sectors where expenditures are most sensitive to changes in consumer confidence $(C N D)$ are most sensitive to one or more types of disasters. Conversely, sectors dependent upon basic areas of consumption, such as consumer staples $(C N S)$, energy $(E N G)$, health care $(H L T)$, telecommunication services (TEL) and utilities (UTL) are generally unaffected by these unsystematic shocks. Further, these sectors are either internationally non-tradeable or with low levels of international trade and so the disruption associated with these disasters are less likely to be associated with export substitution or import replacement. By the same token, the financial services industry has shown itself to be highly sensitive to changes in global macroeconomic conditions, even to 
events such as the September 11 terrorist attacks where the direct impact on the domestic economy are not immediately apparent.

\section{Concluding Remarks}

This study presents an analysis of the impact of natural, industrial and terrorist disasters on the Australian capital market. The data employed consists of daily returns in ten market sectors: namely, consumer discretionary, consumer staples, energy, financial, health care, industrial, information technology, materials, telecommunication services and utilities. Intervention (or impact) analysis based an autoregressive moving average (ARMA) models augmented with dummy variables are used to evaluate the effect of these extraordinary or abnormal events. The most important result of this study is that the shocks provided by natural events and disasters have an influence on market sector returns, depending upon the sector in question. All other things being equal, the sectors most sensitive to disasters of any type are the consumer discretionary, financial services and materials sectors while the most significant single event during the past eight years would appear to be the September 11 terrorist attack, at least in terms of its impact upon the capital market. The apparent sensitivity of the financial services sector in this regard is particularly important given that its ability to withstand and absorb exogenous shocks takes a sequential role in stabilising the financial system, the capital market and the economy as a whole.

Of course, there are a number of limitations in this analysis, all of which suggest future avenues for research. One possibility is that the focus on sectors in this study ignores the fact that at least some disaster impacts may be felt more keenly at the industry level. One obvious example is that a diversification effect may reduce the direct impact via property-liability insurance from including general (non-life) insurance with deposit-taking institutions (such as banks, building societies and credit unions) and other contractual savings institutions 
(including superannuation funds and life offices) in the category of financial services. Another possibility is that even an analysis at the industry level may obscure reactions to disasters at the company level. For example, it is posited that the impact of hurricanes on US propertyliability insurers consisted of both a direct 'market effect' and an indirect 'contagion effect' depending upon exposure to claims in the disaster-affected region [see, for instance, Lamb (1995), Angbazo and Narayanan (1996) and Cagle (1996)]. Future work in this area could then pay more attention to differences across companies including product and factor market location, concentration, diversification, orientation and focus. 


\section{REFERENCES}

Aiuppa, T.A., Carney, R.J. and Krueger, T.M. (1993) An examination of insurer stock prices following the Loma Prieta earthquake, Journal of Insurance Issues, 16(1), 1-14.

Angbazo, L.A. and Narayanan, R. (1996) Catastrophic shocks in the property-liability insurance industry: Evidence on regulatory and contagion effects, Journal of Risk and Insurance, 63(4), 619-637.

Bhar, R. (2001) Return and volatility dynamics in the spot and futures markets in Australia: An intervention analysis in a bivariate EGARCH-X framework, Journal of Futures Markets, 21(9), 833-850.

Box, G.E.P. and Tiao, G.C. (1975) Intervention analysis with applications to economic and environmental problems, Journal of the American Statistical Association, 70(1), 70-79.

Box, G.E.P., Jenkins, G.M. and Reinsel, G.C. (1994) Time Series Analysis Forecasting and Control, PrenticeHall, Upper Saddle River, New Jersey.

Bureau of Transport Economics (2001) Economic Costs of Natural Disasters in Australia, Bureau of Transport Economics Report No. 103, Canberra.

Cagle, J.A.B. (1996) Natural disasters, insurer stock prices and market discrimination: The case of Hurricane Hugo, Journal of Insurance Issues, 19(1), 53-68.

Chen, A.H. and Siems, T.F. (2002) An empirical analysis of the capital markets' response to cataclysmic events. Paper presented at the DIW Economic Consequences of Global Terrorism Workshop, Berlin, 14-15 June.

Emergency Management Australia (2003) <http://www.ema.gov.au/> (accessed August 2003).

Fairbairn, T. J. (1998) Economic consequences of natural disasters among Pacific island countries, Pacific Economic Bulletin, 13(2). 54-63.

Federal Emergency Management Agency (2003) < http://www.fema.gov/> (accessed August 2003).

Fox, R.T. (1995) Measuring catastrophic events on operating viability of firms: Hurricane Hugo and Hospitals, International Advances in Economic Research, 1(3), 251-262.

Fox, R.T. (1996) Using intervention analysis to assess catastrophic events on business environment, International Advances in Economic Research, 2(3), 341-349.

Ho, A.K.F. and Wan, A.T.K. (2002) Testing for covariance stationarity of stock returns in the presence of structural breaks: An intervention analysis, Applied Economics Letters, 9(7), 441-447.

Lamb, R.P. (1995) An exposure-based analysis of property-liability insurer stock values around hurricane Andrew, Journal of Risk and Insurance, 62(1), 111-123.

Liu, Y.J. and Yu, C.H. (2002) On the effect of stock stabilisation fund: A case of Taiwan, Review of Pacific Basin Financial Markets and Policies, 5(1), 93-109.

Miller, R. (1991) Natural disasters and their impact on insurance companies and financial markets, Journal of International Securities Markets, 5(1), 185-189.

Shelor, R., Anderson, D. and Cross, M. (1992) Gaining from loss: Property-liability insurer stock values in the aftermath of the 1989 California earthquake, Journal of Risk and Insurance, 59(3), 476-488.

St. Pierre, E.F. (1998) The impact of option introduction on the conditional return distribution of underlying securities, Financial Review, 33(1), 105-118.

West, J. (2003) Impact of catastrophic loss in insurance security returns. Paper presented to the Business and Economic Society International (BESI) Conference, San Francisco, 24-28 July.

Worthington, A. and Valadkhani, A. (2004), "Measuring the impact of natural disasters on capital markets: an empirical application using intervention analysis, Applied Economics, 36(19), 2177-86. 
TABLE 1. Summary statistics of Australian equity sector returns

\begin{tabular}{lrrrrrrrrrr}
\hline & \multicolumn{1}{c}{ CND } & \multicolumn{1}{c}{ CNS } & \multicolumn{1}{c}{ ENG } & \multicolumn{1}{c}{ FIN } & \multicolumn{1}{c}{ HLT } & \multicolumn{1}{c}{ IND } & \multicolumn{1}{l}{ INF } & \multicolumn{1}{l}{ MTL } & TEL & UTL \\
\hline Observations & 2215 & 2215 & 2215 & 2215 & 2215 & 2215 & 803 & 2215 & 1456 & 1845 \\
Mean & 0.0003 & 0.0002 & 0.0003 & 0.0004 & 0.0002 & 0.0002 & 0.0001 & 0.0001 & 0.0002 & 0.0004 \\
Median & 0.0000 & 0.0000 & 0.0000 & 0.0003 & 0.0000 & 0.0001 & 0.0000 & 0.0000 & 0.0000 & 0.0000 \\
Maximum & 0.2002 & 0.0857 & 0.0924 & 0.0468 & 0.1609 & 0.0904 & 2.5246 & 0.0619 & 0.0833 & 0.0727 \\
Minimum & -0.1306 & -0.0718 & -0.0872 & -0.0559 & -0.0975 & -0.0976 & -0.3339 & -0.0620 & -0.0986 & -0.0847 \\
Standard deviation & 0.0200 & 0.0107 & 0.0140 & 0.0095 & 0.0153 & 0.0105 & 0.0986 & 0.0116 & 0.0156 & 0.0141 \\
Skewness & 0.3981 & 0.0598 & -0.0119 & -0.3369 & 0.7183 & -0.3409 & 20.8943 & 0.0694 & -0.0676 & -0.0552 \\
Kurtosis & 10.4551 & 7.2198 & 5.4877 & 5.3515 & 12.8866 & 10.7892 & 537.3205 & 4.5074 & 5.6185 & 5.9370 \\
Jarque-Bera statistic & $5.19 \mathrm{E}+03$ & $1.64 \mathrm{E}+03$ & $5.71 \mathrm{E}+02$ & $5.52 \mathrm{E}+02$ & $9.21 \mathrm{E}+03$ & $5.64 \mathrm{E}+03$ & $9.61 \mathrm{E}+06$ & $2.11 \mathrm{E}+02$ & $4.17 \mathrm{E}+02$ & $6.64 \mathrm{E}+02$ \\
JP $p$-value & 0.0000 & 0.0000 & 0.0000 & 0.0000 & 0.0000 & 0.0000 & 0.0000 & 0.0000 & 0.0000 & 0.0000 \\
ADF Constant only & -46.1967 & -45.6867 & -44.5064 & -43.9009 & -45.2404 & -47.0810 & -28.7125 & -42.4657 & -36.8058 & -39.0648 \\
ADF Constant and trend & -46.2166 & -45.6872 & -44.5023 & -43.9284 & -45.2463 & -47.1027 & -28.7938 & -42.4601 & -36.9379 & -39.1027 \\
KPSS Constant only & 0.2200 & 0.0915 & 0.0824 & 0.2289 & 0.3040 & 0.2526 & 0.3750 & 0.0829 & 0.7027 & 0.3293 \\
KPSS Constant and trend & 0.0558 & 0.0494 & 0.0551 & 0.0290 & 0.2463 & 0.0555 & 0.1262 & 0.0438 & 0.1329 & 0.0993 \\
\hline
\end{tabular}

Notes: This table presents measures of central tendency, dispersion, shape and the time series properties of returns in the following equity sectors: consumer discretionary (CND), consumer staples (CNS), energy (ENG), financial services (FIN), health care (HLT), industrial (IND), information technology (INF), material (MTL), telecommunication services (TEL) and utilities (UTL). The sample period ends on 30 June 2003 for all series with CND, CNS, ENG, FIN, HLT, IND and MTL starting on 27 January 1995, UTL on 6 May 1996, TEL on 1 December 1997 and INF on 1 June 2000. The critical values of significance for skewness and kurtosis at the .05 levels are 0.1020 and 0.2040 (CND, CNS, ENG, FIN, HLT, IND, MTL), 0.1117 and 0.2235 (UTL), 0.1258 and 0.2516 (TEL) and 0.1694 and 0.3388 (INF) respectively. JB Jarque-Bera. Augmented Dickey-Fuller (ADF) test hypotheses are $\mathrm{H}_{0}$ : unit root, $\mathrm{H}_{1}$ : no unit root (stationary). The lag orders in the ADF equations are determined by the significance of the coefficient for the lagged terms. ADF critical values are $-3.1278,-3.4118$ and -3.9622 at the $.10, .05$ and .01 levels, respectively. KPSS critical values for constant and trend (constant only) are: $0.7390(0.1190), 0.4630(0.1460)$ and $0.3470(0.2160)$ at the $.10, .05$ and .01 levels, respectively. 
TABLE 2. Estimated equations for Australian equity sector returns

\begin{tabular}{|c|c|c|c|c|c|c|c|c|c|c|c|c|c|c|c|}
\hline & Coefficient & Std. error & $p$-value & Coefficient & Std. error & $p$-value & Coefficient & Std. error & $p$-value & Coefficient & Std. error & $p$-value & Coefficient & Std. error & $p$-value \\
\hline & & CND & & & CNS & & & ENG & & & FIN & & & HLT & \\
\hline$\mu_{0}$ & 0.0004 & 0.0004 & 0.3108 & 0.0003 & 0.0002 & 0.2720 & 0.0003 & 0.0003 & 0.3097 & 0.0005 & 0.0002 & 0.0096 & 0.0002 & 0.0003 & 0.4273 \\
\hline$\beta_{1}$ & -0.0101 & 0.0075 & 0.1781 & -0.0029 & 0.0056 & 0.6021 & 0.0112 & 0.0071 & 0.1154 & -0.0002 & 0.0036 & 0.9549 & -0.0046 & 0.0073 & 0.5253 \\
\hline$\beta_{2}$ & -0.0112 & 0.0072 & 0.1237 & -0.0006 & 0.0027 & 0.8159 & -0.0047 & 0.0071 & 0.5087 & -0.0050 & 0.0034 & 0.1381 & -0.0076 & 0.0073 & 0.2953 \\
\hline$\beta_{3}$ & -0.0196 & 0.0157 & 0.2125 & 0.0009 & 0.0048 & 0.8566 & 0.0037 & 0.0071 & 0.6024 & -0.0162 & 0.0048 & 0.0008 & -0.0016 & 0.0073 & 0.8245 \\
\hline$\beta_{4}$ & -0.0016 & 0.0108 & 0.8845 & -0.0014 & 0.0022 & 0.5114 & -0.0031 & 0.0071 & 0.6577 & -0.0105 & 0.0052 & 0.0444 & -0.0054 & 0.0073 & 0.4559 \\
\hline$\beta_{5}$ & -0.0327 & 0.0243 & 0.1788 & -0.0047 & 0.0100 & 0.6406 & -0.0075 & 0.0071 & 0.2881 & -0.0237 & 0.0108 & 0.0287 & -0.0113 & 0.0073 & 0.1210 \\
\hline$\beta_{6}$ & -0.0188 & 0.0054 & 0.0005 & -0.0038 & 0.0023 & 0.1031 & -0.0032 & 0.0071 & 0.6484 & 0.0078 & 0.0056 & 0.1674 & 0.0049 & 0.0073 & 0.4990 \\
\hline$\rho_{1}$ & -0.2529 & 0.0240 & 0.0000 & -1.1959 & 0.0689 & 0.0000 & 0.3443 & 0.0953 & 0.0003 & -0.4848 & 0.0826 & 0.0000 & -0.7512 & 0.0804 & 0.0000 \\
\hline$\rho_{2}$ & -0.7944 & 0.0362 & 0.0000 & -0.6315 & 0.0635 & 0.0000 & -0.6174 & 0.1062 & 0.0000 & -0.4202 & 0.0881 & 0.0000 & 0.7067 & 0.0464 & 0.0000 \\
\hline$\rho_{3}$ & 0.1096 & 0.0250 & 0.0000 & 0.2845 & 0.0661 & 0.0000 & -0.0303 & 0.0185 & 0.1023 & -0.8584 & 0.0738 & 0.0000 & -0.4556 & 0.0940 & 0.0000 \\
\hline$\rho_{4}$ & 0.2001 & 0.0145 & 0.0000 & 0.2936 & 0.0643 & 0.0000 & -0.6221 & 0.0558 & 0.0000 & - & - & - & -0.2903 & 0.0550 & 0.0000 \\
\hline$\rho_{5}$ & - & - & - & -0.3827 & 0.0465 & 0.0000 & -0.4455 & 0.1523 & 0.0035 & - & - & - & - & - & - \\
\hline$\phi$ & - & - & - & 0.0717 & 0.0301 & 0.0173 & -0.0486 & 0.0279 & 0.0814 & -0.0505 & 0.0269 & 0.0604 & -0.0448 & 0.0239 & 0.0614 \\
\hline$\theta_{1}$ & 0.2247 & 0.0241 & 0.0000 & 1.2173 & 0.0665 & 0.0000 & -0.2922 & 0.0908 & 0.0013 & 0.4815 & 0.0888 & 0.0000 & 0.7946 & 0.0773 & 0.0000 \\
\hline$\theta_{2}$ & 0.7758 & 0.0368 & 0.0000 & 0.6386 & 0.0599 & 0.0000 & 0.6031 & 0.1054 & 0.0000 & 0.3997 & 0.0946 & 0.0000 & -0.8052 & 0.0478 & 0.0000 \\
\hline$\theta_{3}$ & -0.0984 & 0.0298 & 0.0010 & -0.3550 & 0.0612 & 0.0000 & 0.6630 & 0.0559 & 0.0000 & 0.8423 & 0.0797 & 0.0000 & -0.0791 & 0.0240 & 0.0010 \\
\hline$\theta_{4}$ & -0.2223 & 0.0194 & 0.0000 & -0.3619 & 0.0602 & 0.0000 & 0.5059 & 0.1530 & 0.0010 & - & - & - & 0.5043 & 0.0892 & 0.0000 \\
\hline$\theta_{5}$ & - & - & - & 0.3807 & 0.0398 & 0.0000 & - & - & - & - & - & - & 0.3200 & 0.0542 & 0.0000 \\
\hline AIC & -5.0050 & - & - & -6.2377 & - & - & -5.7036 & - & - & -6.4851 & - & - & -5.5349 & - & - \\
\hline SC & -4.9662 & - & - & -6.1911 & - & - & -5.6596 & - & - & -6.4489 & - & - & -5.4909 & - & - \\
\hline DW & 2.0042 & - & - & 1.9671 & - & - & 2.0097 & - & - & 1.8992 & - & - & 1.9975 & - & - \\
\hline LR & 5532.9680 & - & 0.0000 & 2.8039 & - & 0.0001 & 2.9474 & - & 0.0001 & 4.7865 & - & 0.0000 & 3.9109 & - & 0.0000 \\
\hline White & 1.6238 & - & 0.0784 & 1.8422 & - & 0.0370 & 0.9174 & - & 0.5284 & 5.0816 & - & 0.0000 & 0.2911 & - & 0.9909 \\
\hline $\mathrm{Q}$ & 31.5270 & - & 0.2940 & 47.2900 & - & 0.0050 & 25.3200 & - & 0.5010 & 39.0980 & - & 0.1000 & 18.1720 & - & 0.8690 \\
\hline \multirow[t]{2}{*}{ LM } & 1.2014 & - & 0.3059 & 1.2147 & - & 0.2995 & 0.4418 & - & 0.8195 & 1.4983 & - & 0.1871 & 0.0587 & - & 0.9978 \\
\hline & & IND & & & INF & & & MTL & & & TEL & & & UTL & \\
\hline$\mu_{0}$ & 0.0002 & 0.0002 & 0.3247 & 0.0002 & 0.0037 & 0.9637 & 0.0001 & 0.0002 & 0.7156 & -0.0004 & 0.0003 & 0.1977 & 0.0004 & 0.0003 & 0.2717 \\
\hline$\beta_{1}$ & 0.0036 & 0.0053 & 0.5022 & - & - & - & 0.0232 & 0.0138 & 0.0926 & -0.0052 & 0.0085 & 0.5402 & 0.0011 & 0.0076 & 0.8875 \\
\hline$\beta_{2}$ & -0.0025 & 0.0053 & 0.6404 & -0.0002 & 0.0508 & 0.9962 & -0.0070 & 0.0040 & 0.0799 & -0.0033 & 0.0029 & 0.2578 & -0.0002 & 0.0076 & 0.9756 \\
\hline$\beta_{3}$ & -0.0001 & 0.0053 & 0.9797 & - & - & - & -0.0046 & 0.0064 & 0.4753 & 0.0051 & 0.0160 & 0.7486 & 0.0017 & 0.0076 & 0.8204 \\
\hline$\beta_{4}$ & 0.0005 & 0.0053 & 0.9278 & -0.0310 & 0.0508 & 0.5423 & -0.0013 & 0.0076 & 0.8601 & -0.0022 & 0.0073 & 0.7659 & -0.0061 & 0.0076 & 0.4176 \\
\hline$\beta_{5}$ & -0.0100 & 0.0053 & 0.0594 & -0.0442 & 0.0508 & 0.3847 & -0.0184 & 0.0103 & 0.0736 & 0.0095 & 0.0151 & 0.5323 & 0.0063 & 0.0076 & 0.4077 \\
\hline$\beta_{6}$ & 0.0029 & 0.0053 & 0.5854 & -0.0002 & 0.0508 & 0.9962 & 0.0084 & 0.0059 & 0.1495 & -0.0024 & 0.0020 & 0.2300 & -0.0051 & 0.0076 & 0.4990 \\
\hline$\rho_{1}$ & -0.3302 & 0.0561 & 0.0000 & 0.7983 & 0.3352 & 0.0175 & -0.2666 & 0.1140 & 0.0194 & -0.2487 & 0.0497 & 0.0000 & 0.0908 & 0.0233 & 0.0001 \\
\hline$\rho_{2}$ & 0.3636 & 0.0244 & 0.0000 & - & - & - & -0.0362 & 0.0195 & 0.0629 & 0.0908 & 0.0515 & 0.0778 & - & - & - \\
\hline
\end{tabular}




\begin{tabular}{|c|c|c|c|c|c|c|c|c|c|c|c|c|c|c|c|}
\hline & Coefficient & Std. error & $p$-value & Coefficient & Std. error & $p$-value & Coefficient & Std. error & $p$-value & Coefficient & Std. error & $p$-value & Coefficient & Std. error & $p$-value \\
\hline$\rho 3$ & 0.6080 & 0.0543 & 0.0000 & - & - & - & -0.4673 & 0.1107 & 0.0000 & 0.2555 & 0.0419 & 0.0000 & - & - & - \\
\hline$\rho_{4}$ & - & - & - & - & - & - & - & - & - & 0.0847 & 0.0447 & 0.0581 & - & - & - \\
\hline$\rho_{5}$ & - & - & - & - & - & - & - & - & - & 0.7486 & 0.0477 & 0.0000 & - & - & - \\
\hline$\phi$ & - & - & - & - & - & - & -0.0491 & 0.0252 & 0.0516 & - & - & - & - & - & - \\
\hline$\theta_{1}$ & 0.3195 & 0.0569 & 0.0000 & -0.7982 & 0.3355 & 0.0176 & 0.3529 & 0.1083 & 0.0011 & 0.0300 & 0.0166 & 0.0712 & -0.0560 & 0.0234 & 0.0168 \\
\hline$\theta_{2}$ & -0.3608 & 0.0253 & 0.0000 & - & - & - & 0.4774 & 0.1047 & 0.0000 & 0.2232 & 0.0432 & 0.0000 & - & - & - \\
\hline$\theta_{3}$ & -0.6104 & 0.0554 & 0.0000 & - & - & - & - & - & - & -0.0941 & 0.0458 & 0.0401 & - & - & - \\
\hline$\theta_{4}$ & - & - & - & - & - & - & - & - & - & -0.2377 & 0.0366 & 0.0000 & - & - & - \\
\hline$\theta_{5}$ & - & - & - & - & - & - & - & - & - & -0.0734 & 0.0402 & 0.0678 & - & - & - \\
\hline AIC & -6.2786 & - & - & -1.7766 & - & - & -6.0968 & - & - & -5.5052 & - & - & -5.6873 & - & - \\
\hline SC & -6.2451 & - & - & -1.7355 & - & - & -6.0631 & - & - & -5.4396 & - & - & -5.6604 & - & - \\
\hline DW & 1.9786 & - & & 2.0327 & - & & 1.9865 & - & & 1.9916 & - & & 1.9937 & - & - \\
\hline LR & 1.5286 & - & 0.1066 & 0.3705 & - & 0.8979 & 5.4517 & - & 0.0000 & 3.7777 & - & 0.0000 & 2.9839 & - & 0.0025 \\
\hline White & 1.0456 & - & 0.4034 & 0.0061 & - & 0.9999 & 11.0120 & - & 0.0000 & 2.7020 & - & 0.0013 & 0.9642 & - & 0.4812 \\
\hline $\mathrm{Q}$ & 37.2450 & - & 0.1700 & 3.7667 & - & 0.9999 & 18.7840 & - & 0.9440 & 32.5910 & - & 0.1420 & 17.1760 & - & 0.9930 \\
\hline LM & 1.2845 & - & 0.2677 & 0.0795 & - & 0.9954 & 1.1375 & - & 0.3382 & 1.3594 & - & 0.2369 & 0.7492 & - & 0.5866 \\
\hline
\end{tabular}

Notes: This table presents estimated coefficients, standard errors and $p$-values for the ARMA models. Dependent variables are returns for the consumer discretionary (CND), consumer staples (CNS), energy (ENG), financial services (FIN), health care (HLT), industrial (IND), information technology (INF), materials (MTL), telecommunication services (TEL) and utilities (UTL) sectors. Disaster equation terms are denoted $\beta_{i}$ where $i=1$ (Sydney hail storm), 2 (Canberra bushfire), 3 (Victorian gas supply crisis), 4 (HIH collapse), 5 (September 11) and 6 (Bali bombing); $\mu_{0}$ is the equation constant; $\rho_{1}, \rho_{2}, \rho_{3}, \rho_{4}, \rho_{5}$ are autoregressive terms and $\theta_{1}, \theta_{2}, \theta_{3}, \theta_{4}, \theta_{5}, \theta_{6}$ moving average terms where the optimal number (number of lags in brackets) and length of lags vary by sector, such that CND = 6,7,8 and 10 (4), CNS (5) = 1,2,6,7 and 9, ENG (5) = 1,2,5,8 and 10, FIN (3) = 3,6 and 9, HLT (3) = 3,6 and 10, IND (3) = 1,3 and 10, INF (1) = 5, MTL (3) = 1,5 and 8, TEL $(5)=2,3,8,9$ and 10 and UTL $(1)=1 ; \phi$ is the seasonal lag term where the optimal lag length (where applicable) is CNS $=9$, ENG $=5$, FIN $=4$, HLT $=4$, MTL $=10$. AIC - Akaike Information Criterion, SC - Schwartz Criterion, DW - Durbin-Watson statistic, LR -Likelihood ratio $F$-statistic and $p$-value, White - White's $F$-statistic and $p$-value, Q - Ljung-Box $Q$-statistic $(l=36)$, LM - Breusch-Godfrey Lagrange multiplier test statistic $(l=5)$. Conventional standard errors and $p$-values for ENG, HLT, IND, INF, and UTL,White's heteroskedastic consistent standard errors and $p$-values for CND, CNS, FIN, MTL and TEL . 
TABLE 3. Joint hypothesis tests for estimated disaster coefficients

\begin{tabular}{lcccccccc}
\hline & \multicolumn{2}{c}{ Natural disasters } & \multicolumn{2}{c}{ Industrial disasters } & \multicolumn{2}{c}{ Terrorist disasters } & \multicolumn{2}{c}{ All disasters } \\
& $F$-statistic & $p$-value & $F$-statistic & $p$-value & $F$-statistic & $p$-value & $F$-statistic & $p$-value \\
\hline CND & 2.0830 & 0.1248 & 0.7877 & 0.4550 & 6.9771 & 0.0010 & 3.2618 & 0.0034 \\
CNS & 0.1622 & 0.8503 & 0.2329 & 0.7923 & 1.4373 & 0.2378 & 0.6002 & 0.7304 \\
ENG & 1.4622 & 0.2320 & 0.2347 & 0.7909 & 0.6671 & 0.5133 & 0.7868 & 0.5802 \\
FIN & 1.1013 & 0.3326 & 7.6253 & 0.0005 & 3.3554 & 0.0351 & 4.0217 & 0.0005 \\
HLT & 0.7470 & 0.4739 & 0.3021 & 0.7393 & 1.4357 & 0.2382 & 0.8240 & 0.5512 \\
IND & 0.3356 & 0.7150 & 0.0044 & 0.9956 & 1.9317 & 0.1451 & 0.7577 & 0.6033 \\
INF & 3.2380 & 0.0398 & 2.8301 & 0.0596 & 0.1858 & 0.8305 & 1.1442 & 0.3346 \\
MTL & 2.9622 & 0.0519 & 0.2700 & 0.7634 & 2.6472 & 0.0711 & 1.9589 & 0.0682 \\
TEL & 0.8220 & 0.4398 & 0.0953 & 0.9092 & 0.9223 & 0.3978 & 0.5450 & 0.7742 \\
UTL & 0.0105 & 0.9896 & 0.3552 & 0.7011 & 0.5742 & 0.5632 & 0.3137 & 0.9301 \\
\hline
\end{tabular}

Notes: This table presents joint hypothesis tests for the estimated disaster coefficients in Table 2. Consumer Discretionary (CND), Consumer Staples (CNS), Energy (ENG), Financial (FIN), Health Care (HLT), Industrial (IND), Information Technology (INF), Material (MTL), Telecommunication Services (TEL), Utilities (UTL). Natural disasters include Sydney hailstorm and Canberra bushfire, industrial disasters include Victorian gas supply crisis and $\mathrm{HIH}$ collapse, terrorist disasters include September 11 and Bali bombing, All disasters include natural, industrial and terrorist disasters. 